\title{
Introduction to Topics in Organizational Systems and Technology Minitrack
}

\author{
Mark Frolick \\ Xavier University \\ Frolick@xavier.edu \\ Kelly Rainer
}

\author{
Auburn University \\ Rainer@business.auburn.edu \\ Jim Ryan
}

\author{
Auburn University at \\ Montgomery \\ jryan@aum.edu
}

This minitrack is special. It is set up to provide a forum for papers in the Organizational Systems and Technology track that do not "fit" exactly in a specific track. We often serve as an incubator for new ideas.

Over the years we have actively solicited nontraditional, imaginative, and thought-provoking research in any IT area. We are particularly interested in papers that break new ground in new areas, or those that apply existing research to new industry groups or fields.

The papers that we accept generally have the following characteristics:
- They are cross-disciplinary - can be disciplines other than MIS.

- They address current topics that are important to today's managers

- They have a practitioner "flavor." Case studies are welcomed, particularly if they propose questions that will stimulate discussion among session attendees.

- They address current topics that are important to today's managers They have a practitioner "flavor." Case studies are welcomed, particularly if they propose questions that will stimulate discussion among session attendees. 